\title{
Chapter 16 \\ From Digital Nature Hybrids to Digital Naturalists: Reviving Nature Connections Through Arts, Technology and Outdoor Activities
}

\author{
L. Edwards, A. Darby, and C. Dean
}

\begin{abstract}
This work considers how the arts and technology in combination can stimulate connections in heritage gardens, and also nurture care for non-human nature. The chapter divides into two overlapping parts. The first part describes and critiques the design of Digital Nature Hybrid artifacts for interpreting gardens and exploring nature. The second part builds on the first by showing how the challenges presented by the Digital Nature Hybrids stimulated the design of Digital Naturalist workshops. It shows the value of combining arts, digital technologies and outdoor activities to support active engagements with non-human nature and to inspire the development of knowledge and skills needed to attend to natural environments. Research through design underpins the way of working and the project uses a critical approach toward technology, to guide the design decisions. One of the insights is the value that adopting this critical approach has in shaping both processes and designs.
\end{abstract}

Keywords Digital nature $\cdot$ Digital Naturalist $\cdot$ Digital design $\cdot$ Digital Nature Hybrids $\cdot$ Design lens $\cdot$ Research through design $\cdot$ Technicity $\cdot$ Focal things Focal practice $\cdot$ Commoditization $\cdot$ Instrumentalism $\cdot$ Non-human nature $\cdot$ Cultural horizon $\cdot$ Hegemonic structures

Received on September 13, 2019. Revised on September 30, 2019. This work was funded by EPSRC's Digital Economy programme (RCUK Grant EP/G037582/1), EPSRC, an EPSRC Senior Fellowship (Grant EP/P002285/1, The Role of Digital Technology in Understanding, Mitigating and Adapting to Environmental Change) and an ESRC Impact Acceleration Account award (for Digital Naturalists: The Lost Sounds).

L. Edwards $(\varangle)$

School of Computing and Communication, Lancaster University, Lancaster, UK

e-mail: liz.edwards@lancaster.ac.uk

A. Darby

Lancaster Institute for Contemporary Arts, Lancaster University, Lancaster, UK

C. Dean

Edge Hill University, Ormskirk, UK

(C) The Author(s) 2020

R. Earnshaw et al. (eds.), Technology, Design and the Arts-Opportunities and Challenges, Springer Series on Cultural Computing, https://doi.org/10.1007/978-3-030-42097-0_16 


\subsection{Introduction}

Digital and other technologies play an increasing role in human life and have become the dominant paradigm in the industrialized world. Technologies shape our movement and interactions, for example, the way we walk through streets, head down, checking our phones. Each technology favors particular senses and pushes and pulls at them for attention. The values and assumptions that are built into technologies are osmosed into society and become accepted as norms by both individuals and wider society, hence shaping the cultural horizon. Once they have been normalized, technologies reproduce themselves because people take them for granted and are conditioned to notice and value the benefits they bring.

Despite widespread acknowledgement of technology's contributions, many writers over the decades, from Simmel [1, 2] and Marcuse [3] to Feenberg [4-6] and Kahn [7, 8] have expressed concern at the effect of technology on humans and nonhuman nature. Some draw attention to the impact of technicity (the prevalence of and reliance upon technology) on the human psyche, others draw attention to the framing of the world that prevails in this paradigm. Common themes are alienation from the self, from others and from the natural world, and a tendency to perceive every thing and every person as a resource to be harnessed and operationalized, and an inability to see this happening from within the system.

The implications are particularly evident in human relationships with the natural world. People spend more time in communion with their digital devices and less time in nature, leading to a loss of familiarity, awareness and care for the natural environment. As people's care for a place dwindles, protection of that environment declines, and people care even less, leading to an exponential cycle of deterioration.

Fortunately, the cycle can be broken, and the cultural horizon can be shifted, for the benefit of humans and non-humans. Feenberg [4-6] argues that technical codes can be reshaped through a democratic, participatory approach. His work builds on Marcuse's [3] which looks to artists to critique and confront systems and structures.

This chapter discusses digital designs which draw on these ideas, embracing criticism of technologies in order to design differently. The aim of these designs is to revive nature connections and re-energize the culture of amateur naturalists, to ensure that the detailed local knowledge needed to safeguard environments and biodiversity is not lost forever. The designs range from Digital Nature Hybrids intended to stimulate senses and raise awareness of gardens and plant heritage to workshops that meld arts, computing and nature encounters to raise levels of engagement and connection to the natural world. These workshops bring together experts from the different domains, and each iteration responds to location, participants and inputs from the particular partners. Beyond the individual workshop, the project's aim is to strengthen a collaborative community of artists, designers, technologists, environmentalists and educators to excite people about exploring their local area and the wildlife around them. 


\subsection{Background}

The Industrial Revolution caused major changes to the economy and society that cascaded down to individuals' everyday life. People moved from the countryside into cities, becoming geographically separated from the natural world. The character of work changed. Agricultural work had flexed in time with natural rhythms of the day, across the seasons, but machine processes exerted a fixed, relentlessly unwavering pattern, increasingly uncoupled from rhythms in the natural world. Previously people made whole things, from start to finish, but the compartmentalized structures necessitated by machine processes fragmented production, which meant workers carried out discrete, repetitive tasks. Workers no longer saw the workflow from the start to finish and this had consequences. They lost the autonomy to manage their time, they became deskilled, and as a result, were less invested in the production process.

Simmel contended that workers experienced a sense of disconnection in work that affected their identity and extended to their sense of self. The intensity of industrial life distracted and bombarded humans [1] to the point where they had no mental space for reflection and they withdrew emotionally from work and other aspects of life, including the natural world. The narrative of disconnection was later revisited by Marcuse [3] in "One Dimensional Man", which described how technological structures overwhelmed life, to the point where anything that did not fit the dominant technological worldview was squeezed out. In this setting, every thing and every person came to be viewed as a resource to be harnessed and operationalized. This created a situation where people were unwittingly trapped and consumed in their never-ending pursuit of a lifestyle, associated with technological progress, which was promoted through advertising and marketing.

Some, like Heidegger [9, 10], have asserted that technology has a particular character that determines these behaviors and it is so pervasive that retreat from technology is the only way to halt disconnection from the natural world, alienation from one's self and damage to the psyche. Heidegger argues that technology induces a mindset in which everything is seen as "standing reserve", a resource to be consumed, and the essence of things is lost or diminished by this mentality. This perspective implies technology is an external force that acts independently of society to determine particular behavior and values. It has since been shown that technology isn't acting alone in determining behavior but is heavily influenced by society [4-6]. Crucially this led to the possibility that digital technologies could be imbued with a different set of values, prompting alternative behaviors.

This chapter discusses research that explores the use of a critical approach to the design of digital technology for interpretation of gardens and the natural world in support of connection to place and non-human aspects of nature. In Marcuse's critique of technological society [3], he framed artists as outsiders, with the distance and perspective necessary to uncover and challenge the pervading conditions that limit human life. Some fields of art and design have become part of the (hegemonic) structures that perpetuate the cycles of desire that Marcuse criticized, exemplified by "affirmative design", which serves the needs of industry without challenging its 
structures $[11,12]$. Critical design, by contrast, asks questions about society, its values and structures and critiques culture through the medium of design. This role has traditionally been the domain of art, so it has been argued that this pushes design toward artistic practice [12]. Dunne and Raby have been drivers of critical design, through projects such as Foragers, which asks questions about humans' futures in the time of food shortage and overpopulation [13]. In recent years speculative design and more specifically design fiction, which challenge the status quo or ask "what if" questions about potential futures that have gained traction.

This chapter describes work that is derived from the same theoretical roots as critical design but diverges in approach. Where critical design critiques society and speculates on futures through designed artifacts, the work discussed in this chapter attempts to design differently, within the parameters of the current world, by using a design lens that keeps the perceived problematic aspects of technology to the fore, while making conscious efforts to address these problems. This approach focuses on the implications of design process as well as design outputs.

The remainder of the chapter discusses practice-based research conducted by the author that explores the use of a critical approach to the design of technology in the context of environmental communication. The research which began as the lead author's thesis research [14] in 2013, and is ongoing as post-doctoral research, can be divided into three phases: a short initial phase of exploration and prototyping; a five-year collaboration with a team of gardeners at a National Trust property in Nottinghamshire; and development of thesis findings as a research strand within a program researching digital technologies and environmental change. The final phase has a primary focus on Morecambe Bay, Lancashire but its reach has expanded across North West England. The research marries the lead author's background as a Secondary School Geography teacher and a Higher Education researcher, lecturer and multimedia designer.

\subsection{The Design Lens}

The design lens draws on recurrent discourse found in critiques of technology, as well as themes that are specific to particular theorists. Some of the original arguments were made prior to the ubiquitous presence of digital technologies, though they retain their relevance. Describing all the design principles and the theories that underpin them is beyond the scope of this chapter, but the following example shows the development of the design lens.

\subsubsection{Technologies, Things, People and Context}

One of the starting points is that technologies differ substantially in character from non-technological “things.” Devices, (Bormann's term for technologies) [15-17], 
are designed to be ubiquitous, so they can easily be used anywhere. The assets they provide are foregrounded, while the controlling mechanisms are hidden away. Without much thought or effort, they become absorbed into the background of our lives. The freedom devices bring comes with a hidden cost. Devices are (intentionally) detached from their context, in order that they can be used anywhere, by anyone but this means they are not rooted in a culture and its values [15-18]. Technological devices are a means of accessing/unlocking resources, be they reserves of fuel or information and as a consequence, they frame everything as a commodity to be consumed. Heidegger calls this "standing reserve" [9] and he believed that this lens prevents us from seeing things in their own right.

By contrast, it is argued that (non-technological, handmade) "things" provoke a different response, because a thing is of its world and is connected to that world by a myriad of social, historical and material threads. Things are indebted to the people, place, environment, history, culture, knowledge and traditions that brought them into being and continue to sustain their life $[19,20]$. When humans encounter a thing, they are momentarily "interrupted" by it. They pause to notice and reflect on it and the world that brought it into being. They see the thing in and of itself [20]. Where technology's lens reveals everything to be a raw material to be harnessed by humankind, in an ongoing, never-ending process, things illuminate the world that surrounds them. Things are seen through their use, but technologies ultimately disappear in their use [19]. Spinosa and Dreyfus [21] suggest that if technical devices could behave more like other "things", humans could be drawn into a positive relationship without themselves being turned into a standing reserve and losing their capacity to be world disclosers. World disclosers [22] is a term used by Heidegger to describe how things in the world become meaningful through everyday human practices. Equipment has a purpose and when someone uses the equipment for the given purpose, it gives an identity to that person [23]. Hence peoples' identities and sense of self are tied to things and practices.

\subsubsection{Focal Things and Focal Practices}

This connects to the concept of focal things and focal practices $[15,16]$. The term derives from the word "focus", which formerly referred a hearth or fireplace, which Borgmann used to illustrate the concept [15]. In the past, a fire was the focal point in a home, and people were brought together around it. It was the focus around which families gathered, shared news, told stories, played games and connected with one another. Maintaining the fire took effort, exertion and learned skills, from cutting and collecting the wood, to cleaning the hearth and setting the fire. The fire and its activities create sensory experiences, from the smells of the burning wood to the feeling of creeping warmth around a room or muscles fatigued from using an ax to split logs. Focal things like fires form a point of convergence for family and community life, and a social world revolves around them. The world is increasingly revealed, as the focal practice is habituated. 
This is contrasted with technologies which require minimal effort, skill and engagement $[15,16]$. Switching on a central heating system does not provide the same level of engagement and heat distributed through radiators allows a family to spread out across different rooms. Central heating gives the liberation of privacy and instant heat, at a cost.

\subsubsection{Commoditization}

Feenberg $[4,5]$ suggests that there are ways to challenge the tendency toward technological de-worlding that results in wholesale commoditization. Rather than stripping away to reduce something to a raw material (termed Primary Instrumentalization), he advocates incorporation of the social into the technical so that technologies reveal more than commodity. Secondary Instrumentalization integrates the social environment, through systemizations that disclose connections to the world, and valuative mediations that provide space for societal values to inform designs.

In pre-industrial times when things were made in the place where they were used, the production networks were short and local cultural values and priorities were integrated and carried through production. In more recent times, technical networks involved in making digital devices are longer, often spanning the globe, and so the societal and cultural meanings and values that ground things and give them meaning beyond that of commodity may be lost along the way [5]. That said, longer production networks potentially involve more people and present increased opportunities for social interventions [5].

Feenberg argues that more voices are needed in the design process to represent a greater range of values and counter the control exerted through technical systems, a concept he called democratic rationality [4, 5]. From this perspective, technologies need to be open enough that they can be shaped or reconfigured by users to reflect their priorities. In this way the social is inevitably part of the design.

\subsection{Using the Critical Lens to Establish Design Guidelines}

Turning theory into practical guides to shape design is subjective because different designers will interpret and emphasize the theory in different ways. This subsection presents some selected design guides from the author's interpretation of the theory above.

Technological devices require little effort and skill so designs should be effortful and encourage skill development.

Traditionally technology designers have determined what a design is and how it is used. This potentially reinforces power inequalities and excludes the input of users who will be affected by design choices. So, technologies should be flexible enough for wider society and users to influence and reshape designs. 
Technologies slip into the background offering easy access to commodity which means there is no pause for interruption and reflection, so we lose sight of things, their world and ourselves. Consequently, designs or design process should create pauses and interruptions that nudge people into noticing things afresh and attending to them with more intent.

Digital technologies don't require deep engagement or connection to community or place so digital technologies should support focal practices and integrate social dimensions.

Technologies have been criticized for creating distance and abstraction. To counter this, designs should be rooted in context by, for example, medium, materials, processes and values. In order for a design to connect to its world, production networks need to be short to stay close to local culture and values.

Sensory stimuli connect people to the world of a thing. Smell, touch and taste are particularly associated with the immediate body space surrounding a person, so they are associated with immediacy and intimate connection. In contrast, visual stimuli are believed to create a sense of distance, between the seer and the seen [24]. Hence designs should encourage more intimate experiences and activate multiple sensory receptors.

\subsection{Artifacts}

These and other criteria informed the design of a series of objects for personal use and for interpretation of a public garden, including the Nature Meditation Egg, the Rhubaphone and Audio Apples [14, 25-28].

The Nature Meditation Egg (Fig. 16.1) was the first artifact made within the initial exploration and prototyping phase. It was designed for personal use by the lead author to explore the relationship between theory and practice in her role as designer-researcher. The Nature Meditation Egg was designed to encourage its user to notice the natural world. This involved the user audio recording the non-human

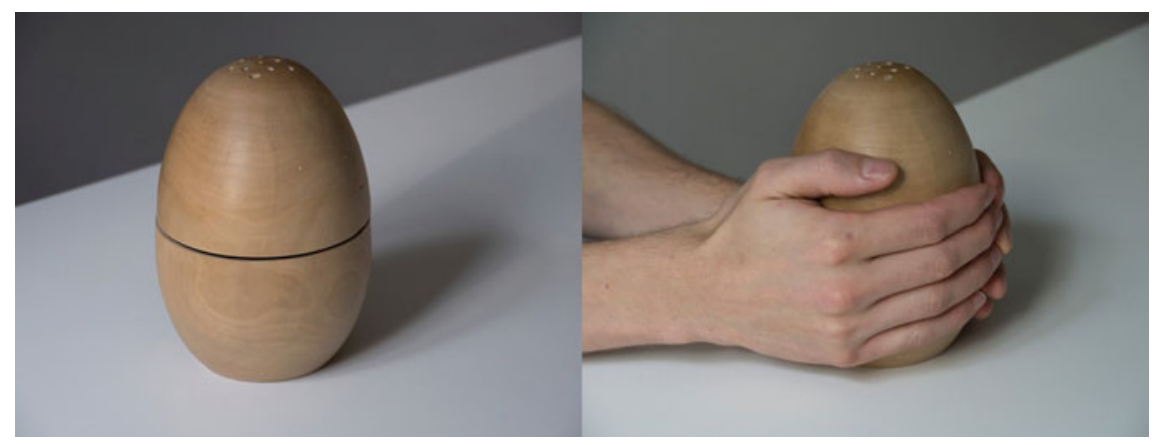

Fig. 16.1 Nature Meditation Egg. Image copyright $\odot$ J. Lindley 2015 and reproduced by permission 
world on a walk in their local area. During meditation, the user would hold an eggshaped wooden object which contained a sensor, microprocessor and audio player. When held with focus for a period of time, the audio from the walk would begin to play. The aims were to stimulate memories of the outdoor experience with the audio, and through the act of recording and listening draw attention to the natural world at a fine level of detail. The wooden egg was turned from local wood by a local joiner, though the digital components were manufactured elsewhere.

The Rhubaphone and Audio Apples were made as digital hybrid interpretation for a public walled kitchen garden, to encourage people to notice it in new ways and support connection to place. The Rhubaphone (Fig. 16.2) was created to bring to attention the individual cultivars in the National Rhubarb Collection, grown in the garden. The Rhubaphone held stems of rhubarb side by side so that differences in size and color were more obvious. Holding a stem activated an audio recording about that variety, its history and cultural significance made by the Head Gardener. The smell of the cut rhubarb and touch of the stem added extra sensory layers to the experience.

The Audio Apples took people into an Apple orchard, that held part of the Regional apple tree collection, but the design also spoke to the past and present of the garden, through audio stories, diary entries, audio recollections and poems recorded by gardeners and volunteers (Fig. 16.3). The wooden Audio Apples hung from branches encouraging visitors to step off the path to reach and pluck them from the tree. Once plucked the different voices of gardeners and volunteers "spoke" to the visitors, through a variety of different kinds of recordings, intended to light a spark in the listener.

The Rhubaphone and Audio Apples used wood from the site and the apples were turned by a member of the team. The heritage of the garden was incorporated through motifs that referenced the garden's past. The design process was shaped to fit the working patterns in the garden and seasonal shifts within the garden. The iterative design process involved feedback and reflections from the Gardens team, and later in the collaboration, a volunteer learned to maintain the digital interpretation artifacts

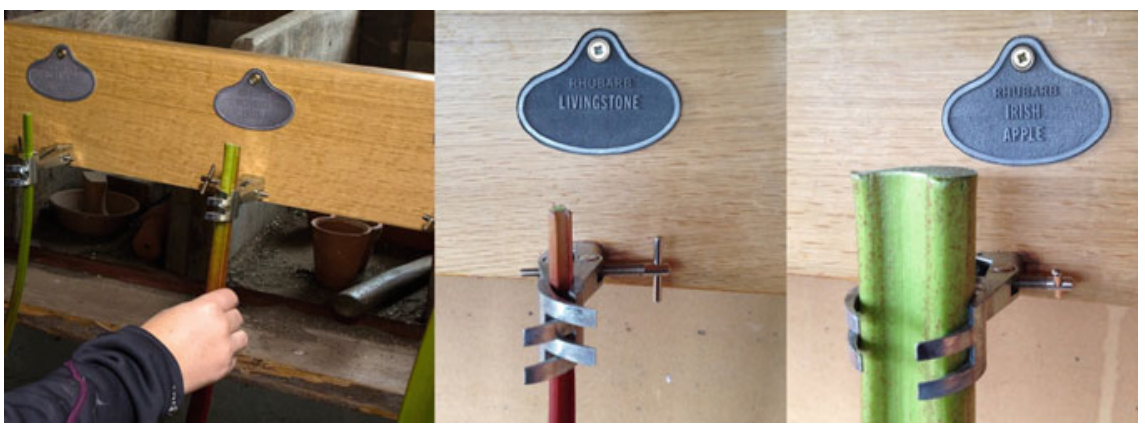

Fig. 16.2 The Rhubaphone in use. (Left) Image copyright @ $\odot$ A. Johnson 2015 and reproduced by permission. Rhubarb cultivars. (Right) Image copyright @ L L. Edwards 2019 


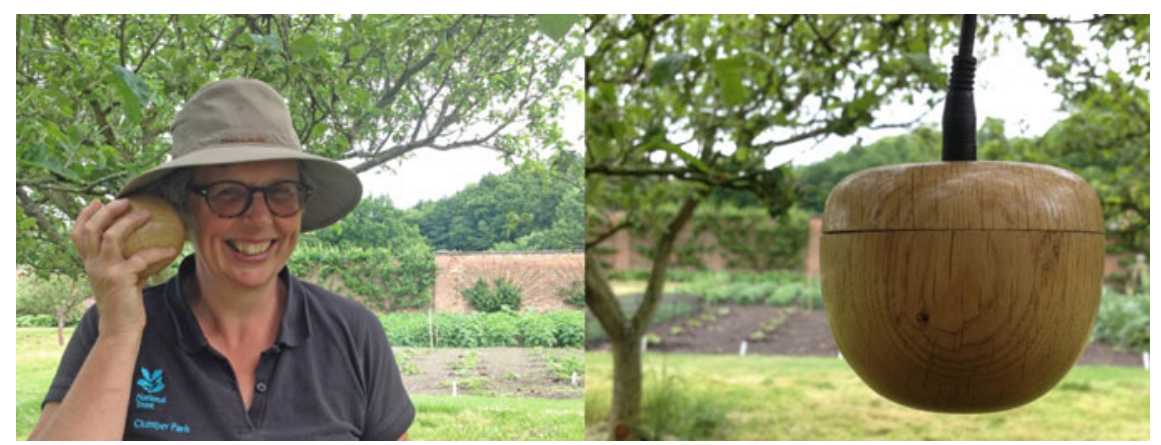

Fig. 16.3 Audio Apples in use. (Left) Audio Apples in the orchard. (Right) Image copyright $\odot$ L. Edwards 2015

and ultimately began to develop content and new ideas. Hence ownership over the artifacts started to shift from researcher-designer to the Gardens team. The software used was open source so that code wasn't locked down and could be adjusted or completely rewritten. Content was stored on SD cards that were familiar to people from everyday use in cameras and phones. This meant people working in the garden could control content with only limited technical expertise. Where possible components were used that could be replaced to extend the life of the design or uncoupled by the team to create new designs. However, through the iterative design process it was found that pre-made boards incorporating microprocessors and sensors were more robust and easier for laypeople to manage. The design and development of these interpretation artifacts is expanded upon in Edwards [14].

\subsection{Reflections on the Digital Nature Hybrid Designs}

Responses to the interpretation and its impact on visitors, volunteers and staff were collected through interviews, field notes and observations. The lead author (in her role as designer-researcher) made notes reflecting on design iterations as part of a research through design $[29,30]$ approach. She participated in the life of the garden and documented and reflected on experiences, conversation and observations in relation to the underpinning theory and practice in notes, audio recording and images made on site, or after visits. The effectiveness of the designs, in conforming to design criteria was evaluated with reference to these reflections as well as theory-driven thematic analysis of interviews with the Gardens team and visitors.

The digital interpretation was positively received. Many visitors commented that they had not previously realized there was more than one variety of rhubarb or they hadn't thought about rhubarb varieties. One of the gardeners said that the process of creating the Audio Apples helped the team realize the value of their stories, and also let them see how their colleagues experienced the garden. Both Audio Apples and 
Rhubaphone prompted a pause in people's passage through the garden, where they stopped and attended to the installations.

The multisensory digital artifacts used touch, smell and sound to encourage a sense of intimacy with the artifact and place. The design criteria resulted in a particular aesthetic, that emphasized materials from the site. It produced technologies rooted in place and not easily used elsewhere. For example, the Rhubaphone incorporated heritage varieties only grown in the garden. Once cut, the rhubarb would begin to wilt and over time it would be unusable. This meant the Rhubaphone could only be used properly within the range of the garden, a characteristic that prioritizes the local and particular.

Overall, the designs cohered with the design lens and had strong contextual relevance. The design processes were a product of place, fitting daily and seasonal patterns in the garden, and respecting the routines and practices of the team. At some points during the collaboration, design and maintenance activities were carried out in a shed in the garden in order to stay connected to the place and enable ongoing input from gardeners and volunteers. This was a response to Feenberg's comments about the benefits of short production networks [5].

Material, software and technological choices were made with the gardeners and volunteers in mind. The question of what would be compatible with their working practices and what they might be able to use independently was kept in the foreground when making design decisions. This enabled a transition toward designs that were initiated by the team, though the team members who managed the digital interpretation artifacts felt more time was needed to build skills to gain more control of the software. The fact the designs were open meant their content could be driven by the team from the ground up, so that their priorities were centered. Stories and content could emerge from the garden.

The interfaces and interactions were described as "fun" and "novel" and they interrupted users, as intended, triggering memories and prompting questions. The use of "actual rhubarb" brought the Rhubaphone to life.

\subsubsection{Challenges Arising Through Use of the Critical Lens}

Although the unfamiliarity of the interfaces caused people to pay attention, it also created barriers to use. The Audio Apples definitely didn't slip easily and effortlessly into the background and this was off-putting for some visitors and therefore potentially problematic for the organization.

The technologies were designed to reveal the world of the garden, its values socially, historically and culturally but there were tensions as the interactive installations could be critiqued as turning the things in the garden into commodities to be consumed by visitors. This conflicts with the aims of the design lens.

The digital interpretation artifacts responded to many of the criteria drawn from the theoretical lens, but they didn't achieve some of the objectives in relation to nurturing connection to place. The digital interactions created a pause, but often 
this was fleeting and superficial and didn't require enough active engagement from participants to really prompt reflection on place. They didn't offer many opportunities for the kinds of extended, embodied engagements that create sensory surprises and experiences which change relationship to place and build emotional connection.

\subsubsection{Response to the Challenges Arising Through Use of the Critical Lens}

The Nature Meditation Egg was designed by its user (the lead author) and the process of designing, creating and using the egg added to a richer understanding of place. The relationship to place was stimulated by the act of design. The process required effort, skill acquisition and significant time spent in a natural environment, which are some of the characteristics of focal practices.

These insights from the Nature Meditation Egg about how the creative process prompted reflection and seeded rich emotional relationships to the land influenced the next phase of work. The realization that the act of designing the artifacts unlocked understanding of place resonated with Heidegger's writings about the nature of humans as world disclosers, who illuminate worlds through practices and make visible the conditions on which things in the world depend. Making artifacts or stories in the garden required the creator to give time to the process and attend to the place. It involved sensory and experiential engagements that prompted emotional connections and a relationship to place. It isn't possible to control placemaking because relationships to place are individual and intangible but there is an argument that some conditions are conducive to nurturing connection. Active engagement appeared to play a significant role, and this insight echoes findings from earlier environmental education projects like Ambient Wood [31].

Reflecting on the initial Digital Nature Hybrid artifacts drove a new research phase about how digital technologies might support active engagement and exploration toward greater awareness of and connection to non-human nature and environments. This led to the inception of the Digital Naturalist program, which began in the public garden where the original work took place but has subsequently been further developed in a range of settings.

\subsection{Digital Naturalists}

The Digital Naturalist program comprises a series of workshops that combine arts activities, with digital making, computer programming, nature walks and fieldwork activities to reveal new perspectives on a place and rekindle naturalist skills. Currently, there are two workshops in the Digital Naturalist program, Digital Boggarts and The Lost Sounds. The program builds on the insights gained from the Digital 
Nature Hybrid artifacts. The pilot project (Digital Boggarts) which began in 2016 extended the collaborative work with the National Trust gardeners and with writers who had developed content for the Audio Apples. The second project (The Lost Sounds) has run in multiple locations across the North West and Midlands with a variety of audiences.

\subsubsection{Background}

The number of amateur naturalists has declined with successive generations [32] and children spend less time playing outside ranging across smaller territories than in previous generations [33]. Consequently, less than a quarter of children regularly use their "local patch of nature", which is half the number in their parents' generation [34]. The Digital Naturalists workshops were designed to explore how digital technologies might be used to stimulate more sustained and effortful interactions in natural environments, with particular attention to sensory awareness. The workshops slow people down in order that they spend time in a place, while the activities aim to tune people into noticing details. The nature walks are led by local experts from environmental organizations in order to raise awareness of local groups. Participants may be more likely to get involved with these groups, as a member or volunteer, if they have made personal contact with someone in the organization.

In the program, digital technologies are used to help people experience the natural world afresh by revealing things that may be otherwise hidden and by supporting the acquisition of traditional skills that bring a new perspective on the natural world. The aim is to inspire a new generation of amateur naturalists and citizens who have increased awareness of their local environments.

Thinking through making is used to focus attention, consolidate knowledge and reflect on a place. The modular structure enables the workshops to be adapted for the specific contexts and audiences. Versions of the workshops have been created for formal and informal education and public engagement settings.

As the workshops have progressed, the importance of sharing the knowledge and products resulting from the workshop, through an exhibition, has become more apparent. The exhibition extends the reach of the program to the wider community beyond workshop attendees and also presents opportunities for workshop participants to act as/or be experts.

\subsubsection{Digital Boggarts}

Boggarts are folkloric creatures, like hobgoblins, that are often associated with a particular location, for example, the Farndale Hob from North Yorkshire [35]. In effect they are spirits of a place. Traditional tales about Boggarts can be found across the United Kingdom making them a useful conduit for talking about place, nature 
and history across the country. The pilot project, Digital Boggarts, drew attention to microclimates and planting within a public garden, and the spirit or feel of the place experienced as a result of these factors (Fig. 16.4).

The project/workshop offered an opportunity to explore a small part of the garden in detail and build an intimate personal relationship with it. This study of a garden at micro level threw into relief the contrasting character, (or spirit) of differing areas within the garden to make these places present to the workshop participant. The Digital Boggart was a manifestation of the kind of creature that might live in that microclimate, a response to the question "Who would live in a place like this?"

At first a wilder setting might seem more suitable than a formal, managed public heritage garden, but many people in the UK have access to a private or communal garden or yard, and gardens are often the most immediate point of contact with non-human nature. The public garden was far larger than a domestic garden but the scale made it easier to identify different microclimates. One of the aims was that participants might start to notice the microclimates and the spirit of different areas within their own gardens or communal spaces. Another aim was to encourage new visitors to the public garden.

Twelve children aged 9-10 from a primary school located close to the public garden took part in the 1.5-day workshop, some was delivered in school, while the major part was delivered in the garden. In school, prior to the garden visit, the children learned to program Micro:bit computers to sense temperature, humidity and direction. The day in the garden began with a guided walk and mapping activity, led by gardeners. This was followed by time exploring the garden with sensors to identify microclimates.

Using information collected in the garden as inspiration, the children worked in groups with a writer to make a fictional story about a Boggart that lived in an area of the garden. They performed the story in the garden and made an audio recording. The children created Boggart creatures from clay, beans, seeds and materials found in the garden, so that the character was rooted in the garden. Each Boggart was given a digital dimension in the form of a Near Field Communication (NFC) tag embedded

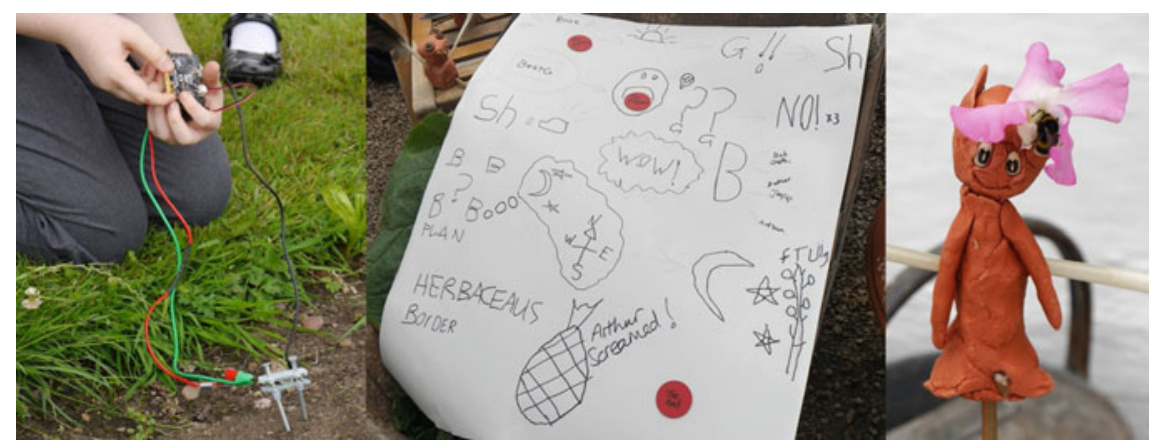

Fig. 16.4 Images from the Digital Boggarts workshop: sensing humidity, story making and a Digital Boggart incorporating Near Field Communication tag. Image copyright @ A A. Darby 2019 
in its body. When the Boggarts were placed on top of upturned flower pots (that housed hidden NFC readers and speakers), the story created by the group played aloud. In effect, the children created a piece of artistic digital interpretation inspired by their experiences and exploration in the garden. Interpretation is commonly used within museums, heritage sites and cultural organizations as a kind of communication that happens in conjunction with direct, firsthand visitor experience. Traditionally, it presented the voice of the expert, in a range of forms but there has been a move toward a more collaborative approach to include more voices alongside that of the trained, experienced interpreter [36, 37]. The idea behind this is the inclusion of excluded histories and the recognition of multiple perspectives on place. Back at school the children made a display of their interactive Digital Boggarts to share stories of the garden with their wider community.

\subsubsection{The Lost Sounds}

The Lost Sounds encourages people to pay attention to the birds in a place through their calls and songs (Fig. 16.5). The name has a twofold meaning. It refers first to the increasing number of birds on the International Union for Conservation of Nature "Red List" of species at risk of extinction. In 2015, 67 of 244 species were on the Red List, compared with 52 species, 6 years before in 2009 [38, 39]. This includes birds such as the Curlew, Nightingale, Merlin and Mistle Thrush. As their numbers decline, their songs and calls are lost to our localities and over time they fade from consciousness. The Lost Sounds is as much about the lost skill of recognizing birdcalls and the songs that are "lost to us" (as the number of amateur naturalists decline) as it is about the loss of particular species.

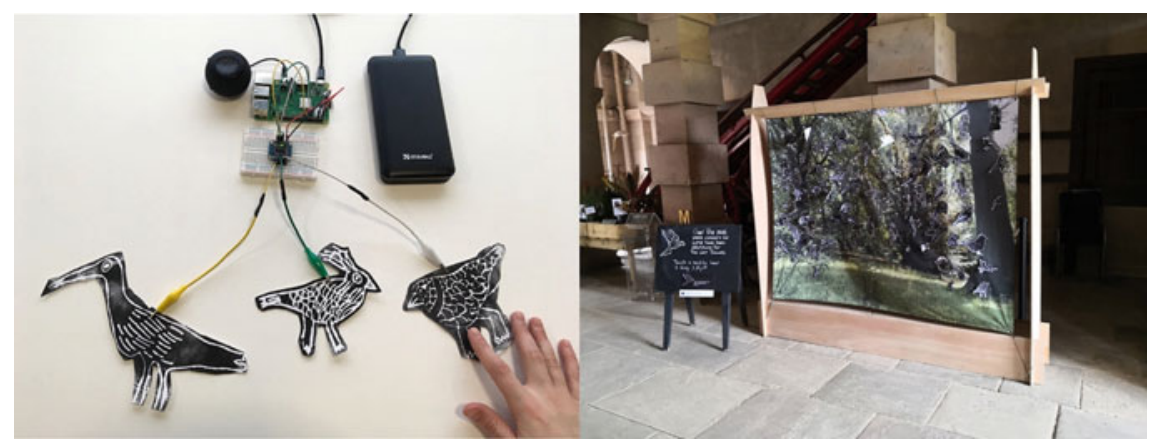

Fig. 16.5 The Lost Sounds interactive birdcall prints. (Left) Image copyright (C) L. Edwards 2019. The Lost Sounds mini exhibition. (Right) Image copyright National Trust Images 2019 and reproduced by permission 
The Lost Sounds [40] has been run in formal education settings at primary schools and a nursery and informal education settings including community festivals and events run in partnership with environmental organizations/charities.

It was originally designed for children in Year 5 targeting Key Stage 2 learning outcomes in computing, art and design, design technology, music and science. It has since been adapted for children in Year 3 and 4, nursery children and family groups. It is also being reconfigured for after school Code Clubs as a way of blending natural history and environmental science into the program. We anticipate compatibility between the structure of Code Clubs and Digital Naturalist workshops that may inspire the development of additional workshops.

The workshop has a similar structure to the Digital Boggarts, involving time spent outside, combined with arts and technology. Specifically, the project includes a guided nature walk, birdwatching, sound recording and editing, listening skills, printmaking, circuit building and computer programming with Scratch running on Raspberry Pi. As before, the aim is to build naturalist skills including careful observation and listening. The full workshop takes 2 or 3 days but shortened one-day and drop-in versions of the workshop have been run in settings where the longer format is unfeasible. This necessitates a smaller range of activities, but the workshop always involves art with technology.

Ideally the workshop begins with a guided walk led by a bird expert or expert in the local environment, but in extreme weather timings may shift. Participants watch for birds with binoculars and take turns with a shotgun microphone and digital audio recorder to listen and make recordings at intervals on the walk. The aim is to use the digital equipment to tune people into their environment and make them more aware of the birdcalls around them. The directional capability of shotgun microphones helps participants to isolate the calls of individual birds, but they don't require the same degree of precision as parabolic microphones. Sight is the dominant sense for most humans [24, 41-43] while sound is omnidirectional and dynamic making it less precise and harder to locate without a visual cue. Locating sound can require practice and effort. Using the microphone gives the holder a temporary "superpower" of enhanced hearing that makes it easier to notice sounds that are initially unfamiliar. As one becomes able to identify individual calls, it is easier to pick them out without the microphone.

After the walk participants draw one of the birds found in the area from pictures, sometimes a bird they have seen or heard. The aim is to look carefully and closely observe the detail of the bird. The drawings (etched into foam) are turned into prints, made with conductive ink. In shorter workshops, participants are taught to recognize selected calls and then pin their print to an interactive sound sculpture, which plays the call of the bird when the print is touched.

In the full workshop, participants either edit their own recordings or the ones made available under a Creative Commons license. They make a circuit with a capacitance sensor attached to the input and output pins of a Raspberry Pi computer and learn to program it to play appropriate calls when prints are touched.

After these workshops, the participants' prints and edited audio are transferred to an installation comprising: Bare Conductive Touch Boards, speakers and fabric print 
of a location visited during the workshop. The installation acts as a mini exhibition of the outputs of The Lost Sounds workshop and it encourages involvement from the wider community beyond workshop participants, (for example, parents and other pupils in a school, or National Trust visitors or local residents). The interactive soundscape installation has been designed in a form that is easy for external partners to manage.

\subsection{Reflections on Digital Naturalists}

Both strands of the Digital Naturalist program, Digital Boggarts and The Lost Sounds have been well received by participants, host organizations, teachers and parents in all settings. Focused time spent in place, and time spent reflecting on non-human nature is built into the design of the program, so this inevitably results in a more significant experience for participants than that created by digital nature interpretations alone.

The combination of arts, computing and outdoor experiences is particularly potent because the digital technologies like the audio recorders enable the participant to experience the environment differently and reveal things that it would otherwise be harder to sense. The digital technologies don't supplant the traditional noticing skills but awaken them, whether that is noticing sunny and shady parts of a garden or using directional microphones to pick out the sounds of individual birdcalls. The digital technologies are intended to encourage people to spend time outside in a focused way. This doesn't have the value of habitual focal practices, but it does require effort while also contributing to skill acquisition that can change a person's relationship to a place and potentially their relationship to technologies.

Creative practices require different kinds of engagement. The drawing encourages the participant to look carefully and notice the difference and the printmaking asks people to think about the character and signs that communicate the essence of a bird species. To write the Boggart stories, people have to think imaginatively about the space which goes beyond recalling facts. The story outcomes may start from jumping off points in a world that is close to the reality of the garden and then shift into realms of fantasy, but both have an impact on the memory of the children and the connections they make to the garden. A translation occurs as the participants turn what has been shared with them into something that they own, and that process involves the investment of the participants.

The layered activities provide different hooks for individuals. Some respond to the making activities, while others are drawn to computing, but the combination is intended to make each activity more appealing to a wider audience. The intention is to consider how this interdisciplinary approach affects perceptions, particularly of technology, computing and environment.

One of the most significant outcomes has been the impact of the sound installation that creates a mini exhibition of project work. These have been left in schools or National Trust properties for days or weeks after a workshop to open the project out to wider audiences who did not participate directly in the workshops. In schools, 
teachers and children talked about the pride of showing their creations to others and sharing the birdcalls they had learned. The fact that the fabric image was of the place where they had spent time outside birdwatching and recording also made it more meaningful. Showing the work to others in the community, for example, at Community Days can start conversations about birds in the area and how to get involved with projects to protect their habitat.

The role of environmental and creative experts is also a key feature of the workshop design. Local environment experts reveal what is hidden or unnoticed and when this is paired well with technologies that also make the invisible visible (or audible), they complement each other powerfully. Creative experts like writers or printmakers introduce ways of seeing that may also unlock new dimensions of non-human worlds. These inspire the active engagements that build care for the non-human world. The creative activities create a space for conversations and questions about ecology and action. Beyond the participants, the workshops bring together organizations and individuals with different competencies who have an interest in the environment, and this has the potential to strengthen networks and seed collaborative action.

The design criteria used at the outset emphasized that the designs should fit the place in which they will be situated. In the earlier Digital Nature Hybrid interpretation, this included using materials from the site and designing artifacts with the local team. This presents a challenge for the Digital Naturalists workshops because they move from place to place. For example, the materials for the exhibition stand cannot come from the location unless the stand is continually remade.

Nevertheless, the Digital Naturalist workshops have been designed to give prominence to place and to respect individual contexts. For example, the Digital Boggarts incorporate materials from the garden in which the Boggarts "live". The fabric backdrop for the Lost Sounds is reprinted with a site-specific photo for new workshop locations. Working with experts from a site and planning the activities with partners who know the location well is another way of ensuring that care for the place is embedded, and that the use of digital technology is appropriate. The combination of arts, outdoor activities and computing is important because at different times each pulls place into focus. That means there is a tension when the shortened versions of the workshops are run because an element is lost that may weaken the connection to place. However, the shortened workshops have prompted bookings for the longer workshops.

One of the ways that Digital Naturalists responds well to the original design lens is that the workshops encourage attention, endeavor and the development of skills. The commitment required in time and effort makes these engagements potentially more meaningful than the brief encounters with the Digital Nature Hybrid interpretation. In both cases, the participant's intent and motivation will affect their experiences. 


\subsection{Conclusions}

Technology has been criticized because of its instrumentalizing tendency, and the implications of that tendency, for example, the increasing separation of humans from non-human nature that results in a lack of care that puts the environment under threat. It also includes the impact on humans' sense of self and well-being. By responding to the criticism directed at technologies through design criteria that referenced the criticism directly, the projects aimed to refocus and reshape priorities and design processes. The simple act of setting the criteria was important for foregrounding the questions, "How are we using digital technologies?" and "What impact is this having on humans and non-humans?"

One of the significant impacts of this lens was the cascade created by prioritizing individual places and rejecting the idea that "one size fits all." Attending to place meant the design process had to respect local ways of working including the rhythms of the place, for example, seasonal and daily working patterns. This in turn influenced digital technology choices and other material decisions which ultimately influenced physical designs and sensory interactions. By attending to place within the design process, the designer-researcher (lead author) became more connected to the places in which she designed. This led to the insight that making in a place and in response to a place could foster a connection and a realization which drove the second phase of research.

The initial Digital Nature Hybrid designs went some way to revealing places and showing non-human nature in a new light. It demonstrated how digital technologies could be rooted in context and culture and how they could amplify particular sensory stimuli to resonate with the sense of place. This in itself had value, for designers, organization and visitors.

However, the engagements with the Digital Nature Hybrids were brief and too superficial to prompt significant change or connection, unless the people concerned were already primed for change or connection. Analyzing the limitations of the Digital Nature Hybrids with respect to the design criteria showed that effort, focus, skill and social connection that made focal things and practices meaningful were less present in the Rhubaphone and Audio Apples and so the question of how to build in these attributes became central to the second phase.

The subsequent projects created deeper, richer encounters with natural environments and showed the power of combining artistic activities with technological activities. The activities required participants to use their technologically amplified senses and creative skills to attend to and reflect on the world.

Using technologies to kindle traditional skills and practices shows one way that technologies might contribute to re-energizing the culture of amateur naturalists and nurture care for non-human nature.

Acknowledgements The work would not have been possible without partners and participants in schools, arts and environmental organizations. I would particularly like to thank the gardeners and volunteer gardeners at National Trust who contributed to this work. 


\section{References}

1. Simmel, G.: The Metropolis and Mental Life. Blackwell Publishing, Oxford (2004)

2. Frisby, D., Simmel, G.: Key Sociologists, 2nd edn. Routledge, London and New York (2002)

3. Marcuse, H.: One Dimensional Man: Studies in the Ideology of Advanced Industrial Society. Routledge \& K. Paul, London (1964)

4. Feenberg, A.: Transforming Technology: A Critical Theory Revisited. Oxford University Press, New York (2002)

5. Feenberg, A.: Between Reason and Experience: Essays in Technology and Modernity. MIT Press, Cambridge, MA (2010)

6. Feenberg, A.: Critical Theory of Technology. Oxford University Press, New York (1991)

7. Kahn, P.H.: Technological Nature: Adaptation and the Future of Human Life. MIT Press, Cambridge, MA (2011)

8. Kahn Jr., P.H., Severson, R.J., Ruckert, J.H.: The human relation with nature and technological nature. Curr. Dir. Psychol. Sci. 18(1), 37-42 (2009)

9. Heidegger, M.: The Question Concerning Technology, and Other Essays. Harper \& Row, New York (1977)

10. Heidegger, M.: Only a god can save us: the Spiegel interview (1966). In: Sheehan, T. (ed.) Heidegger: The Man and the Thinker, pp. 45-68. Routledge, London and New York (2017)

11. Dunne, A., Raby, F.: Critical design FAQ [Online]. http://dunneandraby.co.uk/content/bydandr/ $13 / 0$

12. Gonsher, L.: Beyond Design Thinking: An Incomplete Design Taxonomy [Online]. http:// www.cd-cf.org/articles/beyond-design-thinking/

13. Dunne, A., Raby, F.: Designs for an overpopulated planet: Foragers (2009) [Online]. http:// dunneandraby.co.uk/content/projects/510/0

14. Edwards, E.: Designing contextually relevant digital interpretation for a public garden, HighWire Centre for Doctoral Training, Dept. Computing and Communications, Lancaster University, UK (2019)

15. Borgmann, A.: Technology and the Character of Contemporary Life. University of Chicago Press, Chicago (1984)

16. Borgmann, A.: The moral complexion of consumption. J. Consum. Res. 26(4), 418-422 (2000)

17. Borgmann, A.: Orientation in technology. Philos. Today 16(2), 135-147 (1972)

18. Borgmann, A.: Reality and technology. Camb. J. Econ. 34(1), 27-35 (2010)

19. Edwards, J.C.: The thinging of the thing: the ethic of conditionality in Heidegger's later work. A Companion to Heidegger, pp. 456-467 (2005)

20. Heidegger, M.: Building dwelling thinking. Poetry, Language, Thought, vol. 154 (1971)

21. Dreyus, H.L., Spinosa, C.: Highway bridges and feasts: Heidegger and Borgmann on how to affirm technology. Man World 30(2), 159-178 (1997)

22. Heidegger, M.: Being and time. A Revised Edition of the Stambaugh Translation. Suny Press (2010). First published (1927)

23. Spinosa, C., Flores, F., Dreyfus, H.L.: Entrepreneurship, Democratic Action, and the Cultivation of Solidarity: Disclosing New Worlds. MIT Press, Cambridge, MA (1997)

24. Rodaway, P.: Sensuous Geographies: Body, Sense and Place. Routledge, London and New York (2002)

25. Edwards, E., Coulton, P., Darby, A., Chiasson, M.: Planting and tending digital-nature hybrids in a walled kitchen garden. Des. Issues 33(3), 65-78 (Summer, 2017)

26. Edwards, L., Coulton, P., Chiasson, M.: The inclusions afforded by a value-led design process for technology-nature hybrids in a walled kitchen garden. In: Proceedings of 11th European Academy of Design Conference, Paris, France (2015)

27. Edwards, L., Coulton, P., Chiasson, M.: Walking off the garden path: a design journey. In: Proceedings of Research Through Design Conference, Cambridge, UK (2015)

28. Edwards, E., Coulton, P., Chiasson, M., Darby, A.: Growing an interpretation ecology in a walled kitchen garden. In: Proceedings of the 2014 Companion Publication on Designing Interactive Systems. ACM, Vancouver, Canada, pp. 65-68 (2014) 
29. Frayling, C.: Research in art and design. R. College Art Res. Pap. 1(1) (1993/94) [Online]. http://researchonline.rca.ac.uk/384/3/frayling_research_in_art_and_design_1993.pdf

30. Durrant, A.C., Vines, J., Wallace, J., Yee, J.S.: Research through design: twenty-first century makers and materialities. Des. Issues 33(3), 3-10 (Summer, 2017)

31. Rogers, Y., Price, S., Fitzpatrick, G., Fleck, R., Harris, E., Smith, H., Randell, C., Muller, H., O'Malley, H.C., Stanton, D. et al.: Ambient wood: designing new forms of digital augmentation for learning outdoors. In: Proceedings of the 2004 Conference on Interaction Design and Children: Building a Community. ACM, pp. 3-10 (2004)

32. Moss, S.M.: Natural Childhood. National Trust, London (2012)

33. Louv, R.: Last Child in the Woods: Saving Our Children from Nature-Deficit Disorder. Algonquin Books, New York (2008)

34. Pretty, J., Angus, C., Bain, M., Barton, J., Gladwell, V., Hine, R., Pilgrim, S., Sandercock, S., Sellens, M.: Nature, childhood, health and life pathways. Interdisciplinary Centre for Environment and Society Occasional Paper 2009-02. University of Essex, UK (2009)

35. The Farndale Hob [Online]. http://www.farndalefamily.co.uk/Other/The\%20Farndale\% 20Hob.htm

36. Silberman, N.A.: Heritage interpretation as public discourse: towards a new paradigm. In: Marie-Theres, A., Bernecker, R., Britta, R. (eds.) Understanding Heritage, pp. 21-33. DeGruyter, Berlin (2013)

37. ICOMOS: The ICOMOS charter for the interpretation and presentation of cultural heritage sites. Technical Report. International Council on Monuments and Sites, Charenton-le-Pont, France (2008) [Online]. http://icip.icomos.org/downloads/ICOMOS_Interpretation_Charter_ ENG_04_10_08.pdf

38. Hayhow, D.B., Burns, F., Eaton, M.A., Al Fulaij, N., August, T.A., Babey, L., Bacon, L., Bingham, C., Boswell, J., Boughey, K.L., Brereton, T., et al.: State of Nature 2016. The State of Nature partnership (2016) [Online]. https://www.rspb.org.uk/globalassets/downloads/ documents/conservation-projects/state-of-nature/state-of-nature-uk-report-2016.pdf

39. Eaton, M., Aebischer, N., Brown, A., Hearn, R., Lock, L., Musgrove, A., Noble, D., Stroud, D., Gregory, R.: Birds of conservation concern 4: the population status of birds in the UK. Channel islands and Isle of Man. British Birds 108, 708-746 (2015)

40. Edwards, E.: The Lost Sounds (2019) [Online]. http://www.thelostsounds.org/

41. Tuan, Y-F.: Space and Place: The Perspective of Experience. University of Minnesota Press (1977)

42. Lewis, N.: The climbing body, nature and the experience of modernity. Body Soc. 6(3-4), 58-80 (2000)

43. Ingold, T.: Culture on the ground: the world perceived through the feet. J. Mater. Cult. 9(3), 315-340 (2004)

Open Access This chapter is licensed under the terms of the Creative Commons Attribution 4.0 International License (http://creativecommons.org/licenses/by/4.0/), which permits use, sharing, adaptation, distribution and reproduction in any medium or format, as long as you give appropriate credit to the original author(s) and the source, provide a link to the Creative Commons license and indicate if changes were made.

The images or other third party material in this chapter are included in the chapter's Creative Commons license, unless indicated otherwise in a credit line to the material. If material is not included in the chapter's Creative Commons license and your intended use is not permitted by statutory regulation or exceeds the permitted use, you will need to obtain permission directly from the copyright holder. 